ARTIGO ORIGINAL

\title{
Aspectos que dificultam o tratamento do adolescente usuário de crack na rede de atenção psicossocial
}

\author{
Aspects hindering the treatment of the adolescent crack user in the psychosocial care \\ network
}

\section{Aspectos dificultadores del tratamiento del adolescente usuario de crack en la red de atención psicosocial}

Ribeiro, Juliane Portella ${ }^{1}$; Gomes, Giovana Calcagno²; Mota, Marina Soares ${ }^{3}$; Lopes, Karen Barcelos ${ }^{4}$

Como citar este artigo: Ribeiro JP, Gomes GC, Mota MS, Lopes KB. Aspectos que dificultam o tratamento do adolescente usuário de crack na rede de atenção psicossocial. J. nurs. health. 2019;9(3):e199303

\section{RESUMO}

Objetivo: identificar os aspectos que dificultam o tratamento do adolescente usuário de crack na Rede de Atenção Psicossocial. Método: estudo exploratório e descritivo com abordagem qualitativa. Participaram 14 usuários, 11 familiares e 20 profissionais do Centro de Atenção Psicossocial Álcool e Drogas. Os dados foram coletados por meio de entrevista semiestruturada e, posteriormente, submetidos a Análise Temática. Resultados: emergiram as temáticas: características e comportamento do adolescente; necessidade de adesão voluntária ao tratamento; inespecíficidade das atividades terapêuticas do Centro para o tratamento de adolescentes; demora no atendimento no Centro; fissura; preconceito, rótulo e discriminação do usuário de droga; despreparo profissional para o trabalho com usuários de álcool e droga; e desestruturação familiar. Conclusões: salienta-se a importância de considerar as especificidades e instabilidades dessa faixa etária na organização do atendimento e na elaboração do plano terapêutico singular, de forma a favorecer sua adesão ao tratamento.

Descritores: Adolescente; Cocaína crack; Centros de tratamento de abuso de substâncias; Reabilitação psiquiátrica; Saúde mental.

\section{ABSTRACT}

Objective: to identify the aspects hindering the treatment of the adolescent crack user in the Psychosocial Care Network. Method: exploratory and descriptive study with a qualitative approach. Participants were 14 users, 11 family members and 20 professionals of the Psychosocial Care Network for Alcohol and Drugs. Data were collected through semi-structured interviews, and then submitted to Thematic Analysis. Results: the following topics emerged: the adolescent's characteristics and behavior; need for voluntary treatment adherence; non-specificity of the therapeutic activities of

\footnotetext{
1 Enfermeira e Psicóloga. Doutora em Enfermagem. Universidade Federal de Pelotas (UFPEL). E-mail: ju_ribeiro1985@hotmail.com http://orcid.org/0000-0002-1882-6762

2 Enfermeira. Doutora em Filosofia. Universidade Federal do Rio Grande (FURG). E-mail: giovanacalcagno@furg.br http://orcid.org/0000-0002-2464-1537

3 Enfermeira. Doutora em Enfermagem. Universidade Federal do Rio Grande (FURG). E-mail: msm.mari.gro@gmail.com http://orcid.org/0000-0002-5717-9406

4 Discente do curso de Enfermagem. Universidade Federal de Pelotas (UFPEL). E-mail: karenbarcelos1@hotmail.com http://orcid.org/0000-0003-0734-938X
} 


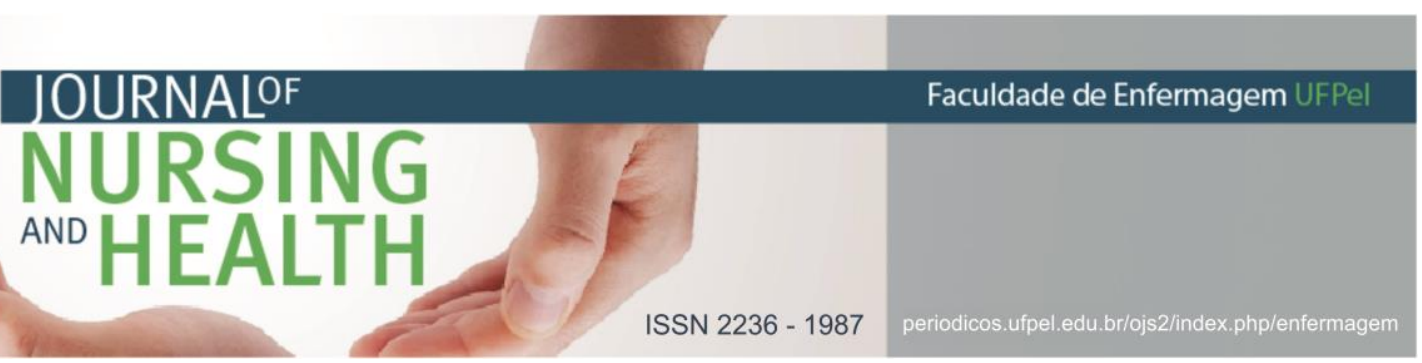

Center for the treatment of adolescents; delay in care in Center; breach; prejudice, labeling and discrimination of the drug user; professional unpreparedness for working with alcohol and drug users; and family breakdown. Conclusions: we highlight the importance of considering the specificities and instabilities of this age group in organizing care and developing a peculiar therapeutic plan, in order to foster its treatment adherence.

Descriptors: Adolescent; Crack cocaine; Substance abuse treatment centers; Psychiatric rehabilitation; Mental health.

\section{RESUMEN}

Objetivo: identificar los aspectos que obstaculizan el tratamiento del adolescente usuario de crack en la Red de Atención Psicosocial. Método: estudio exploratorio-descriptivo con enfoque cualitativo. Participaron 11 usuarios, 14 familiares y 20 profesionales del Centro de Atención Psicosocial Alcohol y Drogas. Los datos se recopilaron mediante entrevista semiestructurada y, posteriormente, se sometieron al Análisis Temático. Resultados: emergieron las temáticas: características y comportamiento del adolescente; necesidad de adhesión voluntaria al tratamiento; inespecificidad de actividades terapéuticas del Centro para el tratamiento de adolescentes; retraso de la atención en el Centro; fisura; prejuicio, rotulación y discriminación del usuario de drogas; falta de preparación profesional para el trabajo con usuarios de alcohol y drogas; y desestructuración familiar. Conclusiones: se subraya la importancia de considerar las especificidades e inestabilidades de esa franja etaria para organizar la atención y desarrollar un plan terapéutico unipersonal, con miras a favorecer su adhesión al tratamiento.

Descriptores: Adolescente; Cocaína crack; Centros de tratamiento de abuso de sustancias; Rehabilitación psiquiátrica; Salud mental.

\section{INTRODUÇÃO}

O World Drug Report, publicado em 2018 pelo United Nations Office on Drugs and Crime (UNODC) apontou uma tendência crescente no uso de cocaína em todo o mundo entre o período de 2006-2016. Além disso, observou-se que o consumo de crack e suas derivações são drogas consumidas majoritariamente por pessoas jovens, quando comparado a demais faixas etárias. ${ }^{1}$

A Pesquisa Nacional sobre o uso de Crack realizada pela Secretaria Nacional de Políticas sobre Drogas (SENAD) e a Fundação Oswaldo Cruz (FIOCRUZ), estimou que nas capitais do Brasil, há cerca de 370 mil usuários de crack, equivalente a $35 \%$ dos usuários de drogas ilícitas nas capitais do país. Destaca-se que a região Sul, junto a região Nordeste, conteve o maior número de usuários de crack e/ou similares, cerca de 150 mil pessoas com uso regular desta droga. ${ }^{2}$

A referida pesquisa também avaliou o quantitativo de usuários de crack e/ou similares que são menores de idade, constatando que dentre os 370 mil usuários de crack e/ou similares estimados, $14 \%$ são menores de idade, 0 que representa aproximadamente 50 mil crianças e adolescentes que fazem uso dessa substância nas capitais do país. Tratase de um achado preocupante, visto que a faixa de menores de 18 anos inclui grupos onde o consumo de crack é nulo (por exemplo, bebês menores de um ano) ou muito baixa/praticamente zero (por exemplo, crianças até oito anos). Isso significa que, se fossem excluídas todas essas crianças de idade 


\section{. \\ ISSN $2236-1987$}

bastante

baixa,

0

consumo proporcional por parte de adolescentes seria mais relevante e mais elevado. ${ }^{2}$

Cabe destacar que a adolescência é uma fase crítica para o desenvolvimento do cérebro em áreas associadas com a impulsividade e tomada de decisão, além da maturação dos sistemas envolvidos na regulação do comportamento emocional. ${ }^{3}$ Depreende-se, assim, que a fase da adolescência necessita de cuidado, amparo e proteção, pois encontra-se mais vulnerável e propenso ao consumo de drogas pelas características da fase de desenvolvimento.

O Crack é uma substância de alto grau de dependência, no qual o usuário de crack se sobressai no que se refere a danos ao próprio indivíduo, complicações com a família, social e de saúde, implicando nas diversas interfaces da vida cotidiana. ${ }^{4}$ Estudo realizado em São Paulo, no qual foram analisadas internações por uso de substancias, constatou que $30 \%$ eram referentes ao Crack. ${ }^{5}$

Tal fato indicou de modo inequívoco a gravidade do problema no país, uma vez que cada internação relacionada ao consumo de drogas implica em custo econômico para o sistema de saúde, mas também significa alto grau de sofrimento individual e para a família daquele que é internado. Assim, as internações compulsórias só devem ser utilizadas em circunstâncias claramente definidas como excepcionais e respeitando os direitos humanos. ${ }^{5}$

Com isso, o Ministério da Saúde divulgou a Política Nacional de Saúde Mental, Álcool e Outras Drogas, juntamente com a Lei 10.216/2001, que implementa os direitos das pessoas com transtornos mentais e transtornos decorrentes do consumo de álcool e outras drogas, o acesso universal, assegurando o direito à assistência, assim como redireciona o modelo assistencial, antes hospitalocêntrico, visando uma rede com diversos serviços de base comunitária e territorial. ${ }^{6}$

Para tanto, a Portaria 3.088/2011 estabelece a Rede de Atenção Psicossocial (RAPS) para pessoas com sofrimento ou transtorno mental e com necessidades decorrentes do uso de crack, álcool e outras drogas. A Rede é composta por serviços e equipamentos variados, tais como: os Centros de Atenção Psicossocial (CAPS); os Serviços Residenciais Terapêuticos (SRT); os Centros de Convivência e Cultura, as Unidade de Acolhimento (UA), e os leitos de atenção integral (em Hospitais Gerais, nos CAPS III). ${ }^{7}$

Com a RAPS há possibilidade de criação, ampliação e articulação de pontos de atenção à saúde para os adolescentes com necessidades decorrentes do uso de crack, pensando diversas estratégias possíveis de suporte por meio da integração de pontos de atenção. 6 No entanto, é notória a lacuna existente na RAPS quanto ao cuidado do adolescente usuário de drogas. Tal entendimento se sustenta no fato de que ainda é incipiente a instalação de serviços especializados a esta população, tanto que o Centro de Atenção Psicossocial Infantil (CAPSi) como o Centro de Atenção Psicossocial Álcool e Drogas (CAPSad) atendem esse público, o que, consequentemente, favorece a 


\section{JOURNALOF

fragmentação e a desresponsabilização pela assistência e pelo cuidado. ${ }^{8}$

Nesse sentido, pesquisadores expõem a existência de uma distância entre adolescência e serviços de saúde mental. Lacuna que pode se ter por diversos fatores, como pela inexperiência e falta de vínculo com os profissionais, carência no acolhimento, além de uma estrutura não apropriada para atender esse público. ${ }^{9}$

Consoante a esses achados, pesquisa que analisou as características dos serviços públicos de saúde mental (CAPSi, CAPSad, CAPS III) do Estado de Santa Catarina mostrou que ao atender $\mathrm{o}$ adolescente no CAPSad juntamente com os adultos, há uma tentativa forçada de tratá-lo como adulto, o que, possivelmente, acarretará prejuízos a ele, uma vez que apresenta características físicas, sociais e psicológicas ainda em desenvolvimento. Além disso, esse fato pode estar associado à baixa adesão dos adolescentes ao serviço e à precarização de estratégias terapêuticas desenvolvidas para o público juvenil. ${ }^{8}$

Diante das considerações expostas, o presente estudo tem por objetivo identificar os aspectos que dificultam 0 tratamento do adolescente usuário de crack na RAPS. Assim, possibilitando o planejamento e a organização de ações que auxiliem na implementação de processos de singularização da atenção, de forma a melhorar a acessibilidade e a aderência dos adolescentes ao tratamento.

\section{MATERIAIS E MÉTODOS}

Trata-se de um estudo descritivo e exploratório com abordagem qualitativa dos dados, vinculado a um projeto de pesquisa amplo, desenvolvido em um município de médio porte do interior do Rio Grande do Sul que integra o Programa "Crack, é possível vencer".

O CAPSad foi elegido como local de coleta de dados, uma vez que o mesmo possui especificidades distintas da pluralidade dos demais serviços que compõem a Rede de Atenção Psicossocial (RAPS) do município.

Participaram do estudo 14 usuários, 11 familiares e 20 profissionais atuantes no CAPSad, totalizando 45 participantes. A seleção dos participantes foi intencional, de acordo com os critérios de inclusão e objetivos da pesquisa.

Para os usuários, os critérios de inclusão foram: ser adolescentes com histórico de uso de crack atendido no CAPSad; ter entre 10 e 20 anos incompletos. Foram excluídos do estudo os adultos usuários do serviço, bem como os adolescentes que estavam hospitalizados em leitos de enfermarias especializadas ou em comunidades terapêuticas e impossibilitados de comparecer a entrevista.

Para os familiares, os critérios de inclusão foram: ter idade mínima de 18 anos; ser familiar do usuário e responsável pelo tratamento do adolescente no CAPSad. Foram excluídos do estudo familiares cuidadores eventuais do usuário. 


\section{JOURNALOF \\ NURSING \\ AND HEALTH}

ISSN 2236 - 1987

Para garantir o anonimato dos participantes empregou-se a letra $A$ para os adolescentes usuários do CAPSad, $F$ para os respectivos familiares e $P$ para os profissionais do serviço, sucedidas do número da entrevista.

Foram respeitados os preceitos éticos para a realização de pesquisa envolvendo seres humanos, conforme a Resolução $n^{\circ} 466$, de 12 de dezembro de 2012. 0 projeto foi encaminhado ao Comitê de Ética em Pesquisa e aprovado mediante o Certificado de Apresentação para Apreciação Ética (CAEE) $\quad n^{\circ} \quad 60649016.9 .0000 .5324$, Parecer $n^{\circ} 4 / 2017$.

\section{RESULTADOS}

Com vistas à privacidade dos participantes, as entrevistas foram realizadas em uma sala do serviço, respeitando a disponibilidade e funcionamento do CAPSad. O estudo teve como questão disparadora: "Fale sobre o modo como você percebe a forma de atendimento e tratamento oferecidos pelos serviços de saúde mental (expectativas, frustrações, efetividade, pontos negativos e positivos)".

Para preservar o conteúdo original e aumentar a acurácia dos dados obtidos, as entrevistas foram capturadas por um gravador de áudio e, posteriormente, transcritas na íntegra. Para a organização e tratamento dos dados, empregou-se o software Nvivo 11, programa que auxilia na análise de material qualitativo com ferramentas de codificação e armazenamento de textos. ${ }^{11}$ Sendo, posteriormente, analisados e categorizados conforme a Análise Temática. ${ }^{12}$
A partir análise dos dados, acerca dos aspectos que dificultam 0 tratamento do adolescente usuário de crack na rede de atenção psicossocial, emergiram as seguintes temáticas: características e comportamento do adolescente; necessidade de adesão voluntária ao tratamento; inespecíficidade das atividades terapêuticas do CAPSad para o tratamento de adolescentes; demora no atendimento no CAPSad; fissura; preconceito, rótulo e discriminação do usuário de droga; despreparo profissional para 0 trabalho com usuários de álcool e droga; e desestruturação familiar.

\section{Características e comportamento do adolescente}

Os profissionais do CAPSad revelam que as características e comportamentos próprios da adolescência dificultam a 


\section{IOURNAIOF

compreensão do adolescente em relação a necessidade de tratamento, bem como exige manejo constante e plano de tratamento versátil, que contemple suas especificidades e instabilidades.

Tem muita diferença, por todas as características da própria adolescência, então eles são muito mais questionadores, eles são mais críticos, eles são muito mais valentes. Eles ainda trazem momentos dessa ambivalência de querer e não querer estar ali. Muitas vezes com as crises de identidade, que é a etapa que eles estão vivendo (P9).

O adolescente vem com um turbilhão de coisas junto, então a equipe precisa ter perfil para trabalhar com eles. Eles têm muito mais energia, muito mais agitação, precisa ter muito mais atividades, precisa ter atividades específicas que compensem. Tem o manejo verbal, que é 24 horas, porque tem todas as crises do adolescente, ele forma aquela questão do grupo, daqui a pouco eles formam mini grupos dentro do grupo e aí já complicam (P18).

Depois a gente começa a trazer eles para as atividades que tem no CAPS e atividades fora, porque tem adolescentes que precisam de rua, então tem que ser atividades feitas na rua. A gente usa muito recurso da rua, porque tem a praça, a biblioteca. Tudo que é evento que dá para a gente participar a gente os leva. Isso não é fácil, as atividades precisam de uma mudança o tempo inteiro. Precisa ter muito manejo, pois eles são muito instáveis de humor, uma hora eles querem muito uma coisa $e$ depois não querem mais. Para trabalhar em cima do PTS [Projeto Terapêutico Singular] com eles tem que ser muito versátil, então a gente cria $e$ pensa nesse PTS dentro do CAPS e vê o que tem lá fora (P7).

\section{Adesão voluntária adolescente ao tratamento} do

Os familiares apontam que o fato do tratamento ocorrer mediante adesão voluntária do adolescente constitui-se em uma barreira para que o mesmo se efetive, pois, sua instabilidade faz com que desistam do tratamento. Sem a adesão do adolescente os pais se sentem perdidos, sem saber o que fazer e a que serviço recorrer para tratar 0 adolescente.

A única coisa que eu acho ruim, digamos assim negativa, é que tem que ser por vontade própria. Claro que quando eles querem tudo se torna mais fácil. Mas, às vezes, eles estão numa situação de vulnerabilidade, de risco, até mesmo colocando a própria família em risco e a si mesmo. É assim que eu me sinto: de pés $e$ mãos amarradas, porque ou ele quer ou tu não podes fazer nada. Isso é bem complicado (F5).

Essa dificuldade que a gente tem para internar o filho da gente, para ter onde colocar os filhos da gente, que eles não possam sair. Isso é uma dificuldade. Lá no 
CAPSad é muito bom, mas ele pode sair a hora que ele quer. Isso que é uma dificuldade (F4).

Se ele evita não adianta. Eles têm que querer. Agora já faz quinze dias que meu filho está lá no CAPSad, e duas vezes ele já quis sair, então é muito dificultoso para a gente lidar com eles quando eles pegam esse caminho, é muito difícil (F10).

Inespecificidade das atividades terapêuticas do CAPSad para o tratamento de adolescentes

Os profissionais expõem que 0 adolescente possui especificidades relacionadas à faixa etária que precisam ser consideradas no tratamento ofertado. O CAPSad, pelo fato de ser projetado para o tratamento do adulto, apresenta limitações para atender as necessidades dos adolescentes, principalmente em relação as atividades terapêuticas ofertadas.

Além disso, o compartilhamento do espaço de tratamento com adultos pode gerar conflitos entre os usuários. Por estas razões, o CAPSi é apontado como melhor local de tratamento para o adolescente, considerado faixa etária e atividades desenvolvidas.

O adolescente ele é muito agitado, tem mais energia. Não tem como botar um adolescente aqui junto com o pessoal que tem mais idade, eles já estão mais devagar digamos assim, não aceitam certas atitudes que os adolescentes têm $e$ aí dão confusão (P20).
Acho que seria bem mais motivacional para os adolescentes estarem envolvidos com outros adolescentes, com a mesma faixa etária, porque às vezes eles tem que participar das oficinas junto com outros adultos, e a gente percebe que não é a melhor coisa (P13).

Eu acredito que o CAPSi seria melhor, no sentido de que estaria mais preparado para atender. Inclusive estar preparado para fazer as atividades com esses adolescentes. $O$ que acontece às vezes, esses adolescentes vêm no CAPSad e aquelas atividades não contam para o que eles necessitam. Então, acredito que o CAPSi poderia contribuir com isso, porque eles vão estar preparados para trabalhar a faixa etária (P8).

Na chegada, a gente faz uma consulta de enfermagem, sempre perguntando assim: o que ele gosta de fazer, porque as atividades do CAPS não são muito direcionadas para os adolescentes, por exemplo, eles não são de fazer pinturas, nem de fazer artesanato. Eles até fazem, mas isso é pouco atrativo. Então, a gente tenta encaixar eles nas aulas de música, na academia, que eles gostam, para gastar bastante energia (P7).

\section{Demora no atendimento no CAPSad}

A demora no atendimento é explicitada como uma dificuldade no tratamento pelos adolescentes e seus 


\section{JOURNALOF \\ NURSING \\ ANO HEALTH}

para ir para o hospital

familiares, visto que pode exacerbar agitação nos usuários devido a sua condição clínica e dependência à droga.

É muito ruim, porque tipo, tem que esperar muito tempo. Eles pedem para tu vir às duas horas e te atendem às três (A9).

Só que no CAPS demora demais para atender, ainda mais para quem já tem problema com droga, problema de nervo. Podia ser mais ágil, não demorar tanto, porque eu cheguei lá a partir da uma e meia, foram me atender quatro horas da tarde (F9).

\section{Fissura}

Os adolescentes apontam a dificuldade em manejar a fissura, principalmente devido ao fato de o tratamento estar vinculado a proposta de abstinência a todo tipo de droga. Para eles, o cigarro de tabaco constitui-se no recurso que apresenta maior eficiência para manejar a fissura, por aliviar a ansiedade e agitação decorrentes da abstinência. Por esta razão, acabam abandonando o tratamento no CAPSad ou ainda preferindo tratar-se no hospital psiquiátrico, pois ele permite o uso do cigarro.

Preferia ficar lá [no hospital psiquiátrico] do que aqui. Lá disseram que podia fumar cigarro e aqui não pode (A10).

Tem muitas pessoas que fumam, que não conseguem se segurar porque não pode fumar. Então, por isso que várias pessoas pedem psiquiátrico, porque no hospital psiquiátrico pode fumar, não tem hora. Para mim foi bem difícil ficar nos lugares por causa do cigarro, na CAPSad mesmo eu não consegui ficar (A13).

Por lei, menor não pode fumar. Eles estão pensando que é melhor para a pessoa. Eu acho, que o melhor para pessoa é eles pegar o cigarro e tirar aos poucos, pelo menos vai se acostumando, porque sem cigarro a pessoa fica agitada e não tem nenhum remédio que tire isso. Então, isso daí tinha que mudar um pouco na CAPSad. Eu mesmo parei de usar a droga por causa do cigarro, então eu parei com tudo e fiquei no cigarro. Com o cigarro eu posso ver as pessoas com maconha na minha volta e me oferecem e eu digo não (A4).

O cigarro ajuda bastante, por causa que no meu tratamento eu não voltei a usar droga e estou só com o cigarro. Parece que se me tirarem o cigarro a mente fica doidinha, aí convence qualquer um a usar de novo (A7).

Eu fumo cigarro de vez em quando. Eu fumo o cigarro para esquecer da droga e aqui eu não fumo cigarro. Podiam mudar o negócio de fumar cigarro (A6).

Preconceito, rótulo de
discriminação do usuário de
droga

Os profissionais mencionam que o preconceito que envolve $o$ uso de 


\section{ISSN 2236 - 1987}

drogas, muitas vezes, faz com que o adolescente seja rotulado. Consequentemente, o adolescente não expõe tal problema, evitando 0 tratamento ou as atividades terapêuticas que vincule sua imagem a droga e comprometam seu convívio social.

Em muitos casos a gente tenta encaminhar $o$ usuário para unidade básica e ele chega dizendo que ele não consegue o atendimento, ou que ele não foi bem atendido, porque tem muito estigma em relação aos usuários de $A D(P 6)$.

Se estivessem em um ambiente de atendimento que não tivesse esse rótulo de $A D$, porque isso tem um peso muito grande para sociedade. Tem muita gente que está aqui acolhido que não quer que ninguém saiba, não quer circular, não quer ir lá em baixo porque alguém pode ver que eles estão aqui, porque os adolescentes se preocupam muito com a imagem (P15).

Tem lugares que ainda tem muito preconceito o uso e aí o indivíduo não é visto como pessoa, ele é visto pela substância que ele usa. Então, ele é o 'crackeiro', ele é o maconheiro, ele é o cara que usa a cocaína. Ele não é visto como uma pessoa, ele é visto pela substância que ele usa. Muitas vezes, ele não vai na UBS porque ele é discriminado (P19).
Despreparo profissional para o trabalho com usuários de álcool e droga

O despreparo e a falta de afinidade com a área de saúde mental e álcool e drogas dificultam o entendimento entre os profissionais, a articulação entre os serviços e, consequentemente, o atendimento do adolescente.

O que eu vejo é muita gente que não sabe o que está fazendo. Pessoas que entraram pelo concurso e que não estão capacitados para isso e, muitas vezes, eles não gostam do que fazem, trabalhar com saúde mental e álcool e drogas (P7).

Alguns não se prepararam para atender usuários de drogas e tudo mais com o adolescente. Eles têm medo de atender os usuários de drogas, às vezes, não atendem os usuários de drogas. Nas UBS, nos outros CAPS, não atendem. 0 paciente pode ser esquizofrênico, mas por estar usando crack vem para o $A D$. Então, o que faz diferença, que eu vejo que melhoraria $e$ garantiria $o$ atendimento aos usuários de drogas, seria que quem está na base soubesse atender e lidar com essas pessoas (P13).

\section{Desestruturação familiar}

Os profissionais apontam que a desestruturação familiar, muitas vezes, ocasiona o uso de drogas e dificulta a busca por tratamento devido a fragilidade $\mathrm{da}$ unidade 


\section{ISSN $2236-1987$}

familiar e dos laços construídos. Por esta razão, o tratamento deve ser ofertado não só ao adolescente, mas a família, de forma a fortalecer seus laços e instrumentalizá-la para o tratamento e reabilitação do adolescente.

Ele já vem de uma família não muito estruturada. A gente vê a maioria, não todos, mas uma grande parte deles, a mãe que tem um filho de cada pai, largam, abandonam, e ou cansaram e não querem mais eles (P19).

Não é à toa que o adolescente usa. Quando tu entras em contato com a família tu vê que é toda uma desestruturação da família (P15).

Então, tem que ser trabalhada toda a questão familiar. A maioria desses casos da nossa unidade não tem pai e mãe. Tem muita relação isso, da falta de estrutura familiar com o uso de drogas, então eu acho que a conduta da equipe tem que ser diferenciada (P16).

Tem aquele grupo de família ali porque não adianta tratar só o adolescente, muitas vezes o problema está lá na família (P20).

\section{DISCUSSÃO}

A adolescência é uma fase do desenvolvimento complexa em que o ser humano precisa lidar com diversas transformações, tanto físicas como psicológicas, que nem sempre são compreendidas pelo jovem. Nessa fase, ocorrem mudanças nos interesses e compreensões sobre a realidade, sobre si e a sociedade que se evidenciam nos comportamentos de constante contestação, curiosidade e experimentação. ${ }^{13}$

Há transformações cerebrais em áreas associadas com a impulsividade e o julgamento, a maturação e o desenvolvimento dos sistemas envolvidos na regulação do comportamento emocional. ${ }^{3}$ Além disso, este período é caracterizado por apresentar conflitos e instabilidades, além de mudanças físicas, psicológicas e emocionais do adolescente. ${ }^{14}$

Por esta razão, ao trabalhar a saúde do adolescente, é necessário reconhecer a imaturidade de seu cérebro, admitindo a ineficiência de alguns programas onde a simples informação de comportamentos de risco não é suficiente para alterar conduta de risco, visto que estão em um ponto de desenvolvimento em que é fácil despertar e difícil controlar os impulsos de excitação. ${ }^{15}$

Não raro, adolescentes que necessitam de tratamento por uso de drogas não se envolvem com o mesmo, fato que restringe sua exposição a intervenções que possam beneficiá-lo e trazer resultados a sua reabilitação e reinserção social. ${ }^{16}$ Para favorecer a adesão do adolescente ao tratamento, os participantes do presente estudo apontam a necessidade de que as intervenções adotadas sejam apropriadas a faixa etária, o que exige dos profissionais o desenvolvimento de um plano terapêutico versátil e manejo constante, de maneira que contemple suas necessidades e instabilidades. 


\section{JOURNALOF \\ NURSING \\ ANO HEALTH}

Em relação à política para crianças e adolescentes, existem algumas lacunas no tratamento deste público que levem em conta suas particularidades e singularidade. Serviços desarticulados, profissionais carentes de formação e que busquem considerar os aspectos psicossociais das famílias desassistidas, entendimento da dinâmica do uso e abuso de substâncias e do seu tratamento, e, principalmente, falta de espaços específicos e articulados de cuidado, intervenções e estratégias para os jovens e adolescentes. Outro aspecto a ser considerado no tratamento é a demora no atendimento e início de tratamento, fator que muitas vezes causa desistência ou recaídas.17-18

Constata-se que há diversas modalidades de tratamento como terapia comportamental, terapia familiar, grupos de 12 etapas, entrevistas motivacionais, gerenciamento de contingência e combinações dessas intervenções que foram modificadas para adolescentes, mas que ainda são subutilizadas, suscitando a conscientização e a implementação desses modelos junto a essa população. ${ }^{19}$

Além disso, a vinculação do tratamento com a abstinência a todo tipo de droga, segundo os adolescentes, dificulta o manejo da fissura. Eles ressaltam que o tabaco é considerado uma fortaleza para lidar com a fissura, pois reduz a ansiedade e agitação decorrentes da abstinência. Em virtude da abstinência exigida abandonam o tratamento. Ao encontro desse achado, pesquisa com o objetivo de identificar o padrão de uso de
ISSN 2236 - 198

outras substâncias psicoativas por usuários de crack em tratamento em um CAPSad evidenciou que o tabaco é a droga mais difícil de largar, sendo frequentemente utilizado durante o tratamento para diminuir a fissura. ${ }^{20}$

Neste sentido, salientasse a importância da estratégia de Redução de danos, que busca a melhoria das condições de vida e saúde e a sobrevivência, visando manter os dependentes inseridos na rede de atenção à saúde e de assistência, evitando a marginalização e evasão do tratamento.

Outro aspecto que pode dificultar a adesão é o fato de o consumo de drogas ser tratado como desvio de conduta, carregado de preconceitos e muitas vezes de rótulos como crackeiro, maconheiro, ladrão e marginal. Por essa situação, o adolescente evita o tratamento ou as atividades terapêuticas que vincule sua imagem a droga e comprometam seu convívio social.

Pesquisadores apontam que à medida que o usuário se torna consciente das visões negativas que as outras pessoas da sociedade têm sobre - uso de drogas ele se sente desestimulado em buscar os serviços, intensificando os problemas de saúde, e quando retornam ao tratamento, a aderência é baixa ao serviço, muitas vezes por um atendimento discriminatória. Além disso, o próprio paciente pode passar a ver-se a partir de uma visão negativa e empregar rótulos negativos, buscando esconder a sua situação dos demais, evitando experiências de preconceito e discriminaçao. ${ }^{21}$ 
O trabalho em saúde mental lida fortemente com assuntos de caráter emocional, não sendo capaz de ser sintetizado apenas a perspectiva técnica. $^{22}$ No entanto, os dados do presente estudo mostram que 0 despreparo e a falta de afinidade com a área de saúde mental e álcool e drogas dificultam 0 entendimento entre os profissionais, a articulação entre os serviços e, consequentemente, o atendimento do adolescente.

Salienta-se que essa realidade é passível de mudança, visto que os profissionais podem beneficiarem-se da educação permanente para suprir essa lacuna na formação, fomentando a reflexão sobre as ações em saúde mental no cotidiano do processo de trabalho, por meio de reuniões de equipe, discussão de casos e temas relevantes a prática, sensibilizando e construindo constantemente profissionais pautados no que preconiza o Modelo de Atenção Psicossocial. ${ }^{23}$

As situações de despreparo e a falta de afinidade com a área pode dificultar a compreensão dos profissionais sobre diferentes aspectos da saúde mental entre eles a intersetorialidade, sobretudo no caso dos adolescentes com problemas por consumo de sustâncias em que a demanda é muito específica. A intersetorialidade, além de ser um dos princípios do trabalho em saúde mental infanto-juvenil, constitui parcerias permanentes com todos os implicados, especialmente com a educação, a assistência social, a justiça e os direitos, setores historicamente relevantes na
ISSN $2236-1987$

assistência às crianças e aos adolescentes, potencializando resultados mais efetivos na assistência infanto-juvenil. ${ }^{24}$

A família é um ponto ambivalente no tratamento da dependência química, especialmente quando se trata de um adolescente. A família que possui estrutura para apoiar o adolescente é, muitas vezes, definidora do sucesso do tratamento. No entanto, famílias desestruturadas, geralmente, não conseguem apoiar o adolescente de forma eficaz o deixando vulnerável, dificultando a busca e até mesmo a continuidade do tratamento devido a fragilidade da unidade familiar e dos laços construídos entre seus membros. Por esta razão, o tratamento deve ser ofertado não só ao adolescente, mas a família, de forma a fortalecer seus laços e instrumentalizá-la para o tratamento e reabilitação do adolescente.

\section{CONSIDERAÇÕES FINAIS}

Os resultados do estudo apontam os aspectos que dificultam o tratamento do adolescente no âmbito da RAPS, salientando a importância de considerar as especificidades e instabilidades dessa faixa etária na organização do atendimento e na elaboração do plano terapêutico singular, de forma a favorecer sua adesão ao tratamento. Além disso, fazse necessário repensar se o modelo de atenção vinculado à abstinência a todo tipo de droga é o mais apropriado, visto que os adolescentes referiram abandonar o tratamento por não poderem utilizar o cigarro de tabaco, considerado o recurso que apresenta 
melhor eficiência para manejar a fissura.

Constatou-se que práticas retrogradas e preconceituosas continuam a permear o tratamento em saúde mental, principalmente quando direcionado a usuários de drogas. Estigmas e discriminação social afastam o adolescente de qualquer serviço de saúde e atividades terapêuticas que o vinculem com a droga e possam comprometer sua imagem e convívio social.

Por esta razão, é imperativo trabalhar no adolescentes habilidades pertinentes ao exercício social e as respostas de enfrentamento a exposição a droga. Também é importante o investimento na capacitação dos profissionais e na divulgação dos serviços que compõem a RAPS para ampliar sua visibilidade e utilização.

\section{FINANCIAMENTO}

0 presente trabalho foi realizado com apoio da Coordenação de Aperfeiçoamento de Pessoal de Nível Superior - Brasil (CAPES) - Código de Financiamento 001.

\section{REFERÊNCIAS}

1 United Nations Office on Drugs and Crime (UNODC). World drug report 2018 [Internet]. 2018[cited 2019 Apr 02]. Available from: https://www.unodc.org/wdr2018/prel aunch/WDR18_Booklet_3_DRUG_MARK ETS.pdf

2 Bastos FI, Bertoni N. Pesquisa nacional sobre o uso de crack. Quem são os usuários de crack e/ou similares do Brasil? Quantos são nas capitais brasileiras? [Internet]. Rio de Janeiro: ICICT/FIOCRUZ; 2014[acesso em 2019 abr 22]. Disponível em: http://conselheiros6.nute.ufsc.br/wp

content/uploads/avea/conteudo/perfi l-brasil.pdf

3 Wu LT, Brady KT, Mannelli P, Killeen TK, Workgroup, NIDAAAPI. Cannabis use disorders are comparatively prevalent among nonwhite racial/ethnic groups and adolescents: a national study. J Psychiatr Res [Internet]. 2014[cited 2018 Oct 03];50(1)26-35. Available from: https://www.ncbi.nlm.nih.gov/pmc/a rticles/PMC3941308/pdf/nihms549837.pdf.

4 Madalena TS, Sartes LMA. Usuários de crack em tratamento em comunidades terapêuticas: perfil e prevalência. Arq. bras. psicol. (Rio J. 2003). [Internet]. 2018[acesso em 02 abril 2019];70(1):21-36. Disponível em: http://pepsic.bvsalud.org/pdf/arbp/v 70n1/03.pdf

5 Bartolomei JR, Rezende LF. Judicialização da saúde e internações Compulsórias de jovens usuários de Drogas: um estudo em espírito santo Do pinhal/sp. Rev. direito sanit. [online]. 2017[acesso em 02 abril 2019];18(2):92-111. Disponível em: http://www. revistas.usp.br/rdisan/ar ticle/view/142025

6 Ministério da Saúde (BR). Secretaria de Atenção à Saúde. Guia estratégico para o cuidado de pessoas com necessidades relacionadas ao consumo de álcool e outras drogas: guia $A D$ [Internet]. Brasília; 2015[acesso em 2019 abr 22]. Disponível em: 


\section{ISSN 2236 - 1987}

http: / / portalarquivos2.saude.gov.br/i mages/pdf/2015/dezembro/15/Guia-

Estrat--gico-para-o-Cuidado-de-

Pessoas-com-Necessidades-

Relacionadas-ao-Consumo-de---lcool-

e-Outras-Drogas--Guia-AD-.pdf

7 Johnson BA, Ait-daoud N, Wang XQ, Penberthy JK, Javors MA, Seneviratne $C$, et al. Topiramate for the treatment of cocaine addiction: a randomized clinical trial. JAMA Psychiatry [Internet]. 2013[cited 2018 Oct 03];70(12):1338-46. Available from: https://jamanetwork.com/journals/ja mapsychiatry/fullarticle/1756816.

8 Bernardi AB, Kanan LA. Características dos serviços públicos de saúde mental (Capsi, Capsad, Caps III) do estado de Santa Catarina. Saúde debate. [Internet]. 2015[acesso em 2018 out 03];39(107):1105-16. Disponível em: http://www.scielo.br/pdf/sdeb/v39n 107/0103-1104-sdeb-39-107-

01105.pdf.

9 Ferreira ACZ, Borba LO, Capistrano FC, Czarnobay J, Maftum. Fatores que interferem na adesão ao tratamento de dependência química: percepção de profissionais de saúde. REME rev. min. enferm. [Internet]. 2015[acesso em 2019 abr 22];19(2):157-65. Disponível em:

http://www.reme.org.br/exportarpdf/1012/v19n2a12.pdf

10 Fontanella BJB, Ricas J, Turato ER. Amostragem por saturação em pesquisas qualitativas em saúde: contribuiçõos teóricas. Cad. Saúde Pública (Online). [Internet]. 2008[acesso em 2019 abril 03];24(1):17-27. Disponível em: https: / /www.scielosp.org/article/csp /2008.v24n1/17-27/pt/

11 Guizzo BS, Krziminski CO, Oliveira DLLC. O Software QSR NVIVO 2.0 na análise qualitativa de dados: ferramenta para a pesquisa em ciências humanas e da saúde. Rev. gaúch. enferm. [Internet]. 2003[acesso em 2018 out 03];24(1):53-60. Disponível em: http: / / seer.ufrgs.br/RevistaGauchade Enfermagem/article/view/4437/2363

12 Minayo ACS. Pesquisa social: teoria método e criatividade. $30^{\mathrm{a}}$ ed. Rio de Janeiro: Vozes; 2011.

13 Filho EAF, Queiros PS, Medeiros M, Rosso CFW, Souza MM. Perceptions of adolescent students about drugs. Rev. bras. enferm. [Internet]. 2015[cited 2018 Oct 03];68(3):517-23. Available from:

http: / /www.scielo.br/pdf/reben/v68 n3/en_0034-7167-reben-68-03-

0517.pdf.

14 Silva AG da, Rodrigues, TCL, Gomes, KV. Adolescência, vulnerabilidade e uso abusivo de drogas: a redução de danos como estratégia de prevenção. Rev. psicol. polit. [Internet]. 2015. [acesso em 2019 abril 03]; 15(33): 335-54. Disponível em: http://pepsic.bvsalud.org/scielo.php? script=sci_arttext\&pid=S1519-

549X2015000200007\&lng=pt\&nrm=iso>

15 Steinberg L. How to improve the health of American adolescents. Perspect Psychol Sci [Internet]. 2015[cited 2018 Oct 03];10(6):711-5. Available from: http://journals.sagepub.com/doi/pdf /10.1177/1745691615598510.

16 Smith DC, Ureche DJ, Davis JP, Walters ST. Motivational interviewing 
with and without normative feedback for adolescents with substance use problems: a preliminary study. Subst Abus [Internet]. 2015[cited 2018 Oct 03];36(3):350-8. Available from: http://doi.org/10.1080/08897077.201 4.988838

17 Passos ICF, Reinaldo MAS, Barboza MAG, Braga GAR, Ladeira KE. A rede de proteção e cuidado a crianças e adolescentes do município de Betim/MG e os desafios do enfrentamento ao uso abusivo de crack, álcool e outras drogas. Pesqui. prát. psicossociais. [Internet]. 2016[acesso em 2019 abril 03];11(3): 583-601. Disponível em: http://pepsic.bvsalud.org/pdf/ppp/v 11n3/05.pdf

18 Paiano M, Maftum MA, Haddad MCL, Marcon SS. Ambulatório de saúde mental: fragilidades apontadas por Profissionais. Texto \& contexto enferm. [Internet]. 2016[acesso em 2019 abril 03];25(3):e0040014. Disponível em: http: / /www.scielo.br/pdf/tce/v25n3/ pt_0104-0707-tce-25-03-0040014.pdf

19 Brewer S, Godley MD, Hulvershorn LA. Treating mental health and substance use disorders in adolescents: what is on the menu? Curr Psychiatry Rep [Internet]. 2017[cited 2018 Oct 03];19(5):1-9. Available from: https: / /doi.org/10.1007/s11920-0170755-0

20 Almeida CS, Luis MAV. Características sociodemográficas e padrão de uso de crack e outras drogas em um CAPS AD. Rev. enferm. UFPE on line. [Internet]. 2017[acesso em 2018 out 03];11(4):716-23. Disponível em: https://periodicos.ufpe.br/revistas/r
evistaenfermagem/article/viewFile/1 $5269 / 18837$.

21 Ronzani TM, Noto AR, Silveira PS. Reduzindo o estigma entre usuários de drogas: guia para profissionais e gestores. Juiz de Fora: Editora UFJF; 2014.

22 Simoes CHD, Fernandes RA, Aiellovaisberg TMJ. O profissional de saúde mental na reforma psiquiátrica. Estud. Psicol. (Campinas, Online). Internet]. 2013[acesso em 2018 out 03];30(2):275-82. Disponível em: http://www.scielo.br/pdf/estpsi/v30 $\mathrm{n} 2 / 14 . \mathrm{pdf}$

23 Bastos IT, Sarubbi VJ, Oliveira TGP, Delfini PSS, Muylaert CJ, Reis AOA. Identity of care in a Psychosocial Care Center for Children and Adolescents who uses drugs. Rev. Esc. Enferm. USP. [Internet]. 2014 [cited 2018 Oct 03];48(2):121-7. Available from: http: / / www.scielo.br/pdf/reeusp/v48 nspe2/0080-6234-reeusp-48-nspe2-

00116.pdf

24 Nunes CK, Kantorski LP, Coimbra VCC. Interfaces between services and actions of the psychosocial care network for children and adolescents. Rev. gaúch. enferm. [Internet]. 2016[cited 2018 Oct 03];37(3):1-8. Available from: http: / / www.scielo.br/pdf/rgenf/v37n 3/en_0102-6933-rgenf-1983144720160354858.pdf

Data de submissão: 10/08/2018 Data de aceite: 04/04/2019 Data de publicação: 14/05/2019 